\title{
New Tea Parental Line, 'MAKURA No. 1', for Breeding Cultivars with High Tannin and Caffeine Contents and a Flowery Flavor
}

\author{
Atsushi NESUMI* and Yoshiyuki TAKEDA \\ Department of Tea, National Institute of Vegetable and Tea Science (NIVTS) \\ (Shimada, Shizuoka 428-8501, Japan)
}

\begin{abstract}
'MAKURA No. 1' (Camellia sinensis var. assamica) is the first tea breeding cultivar that was selected for high tannin and caffeine contents from the genetic resources in the Makurazaki Station of the National Institute of Vegetable and Tea Science (NIVTS). Average tannin and caffeine contents of the 1 st and 2nd crops of this cultivar were 24.6 and 5.5\%, respectively. 'MAKURA No. 1 ' also has a strong floral flavor, and this trait was handed down to the progenies at a certain frequency. The results show that 'MAKURA No.1' can be used as a parental line for breeding cultivars with high tannin and caffeine contents and a floral tea flavor. 'MAKURA No. 1' was named 'Cha Chuukanbohon Nou 3' and registered as a parental line by the Ministry of Agriculture, Forestry and Fisheries (MAFF) in August 1998. It was registered based on the Seed and Seedlings Law in June 2002.

Discipline: Plant breeding

Additional key words: Camellia sinensis, catechins, Cha Chuukanbohon Nou 3, methyl anthranilate
\end{abstract}

\section{Introduction}

Tannin (most precursor components are catechins in tea) and caffeine are important factors that determine the taste of tea ${ }^{7}$. There have been many studies recently on functional ingredients of tea, and these studies have clarified various activities of catechins, including the anti-oxidative, anti-mutation, anti-tumor, anti-allergy, and cholesterol reducing activities, as well as various activities of caffeine, including the stimulant activity, cardiac action and diuretic action 8,12 .

There are about 7,500 individual genetic resources of Camellia sinensis and the genus Camellia in Japan, and about 4,000 of these individual genetic resources are in the Makurazaki Station (NIVTS). Furthermore, most genetic resources of $C$. sinensis var. assamica are kept in Makurazaki. Makurazaki is suitable for keeping genetic resources like var. assamica, because Makurazaki Station is located in the southern part of Kyusyu district which is a place where little or no frost occurs in this major tea area. Breeding tea cultivars with high catechin and caffeine contents is necessary for efficient use of these components and for extending the diversification of taste and aroma in brewed tea ${ }^{10}$. Therefore, we have tried to select high tannin and high caffeine contents in tea genetic resources and crossbreeds at Makurazaki Station.

We succeeded in raising a cultivar that has high tannin and high caffeine contents as well as a flowery flavor. This cultivar, named 'MAKURA No. 1' (C. sinensis var. assamica), was registered as the parental line 'Cha Chuukanbohon Nou 3' in 1998 and was registered as 'MAKURA No. 1' based on the Seed and Seedlings Law in 2002.

\section{Materials and methods}

We investigated tannin and caffeine contents of tea leaves that are conserved as genetic resources at Makurazaki Station of NIVTS in 1990 and 1991. The number of genetic resources analyzed for tannin was 1,472 (C. sinensis var. assamica: 508, var. sinensis (China group: native varieties in China): 292, var. sinensis (Japan group: native varieties in Japan): 672) and the number analyzed for caffeine was 1,526 (C. sinensis var. assamica: 515, var. sinensis (China group): 308, var. sinensis (Japan group): 703). Tannin content was analyzed by the colorimetric determination method, and caffeine

*Corresponding author: fax +81-547-46-2169; e-mail nesuco@affrc.go.jp

Received 28 February 2005; accepted 17 June 2005. 
was analyzed by high-performance liquid chromatography (HPLC) ${ }^{2}$. Contents of catechins in new shoots of the first crop were analyzed by HPLC ${ }^{11}$.

Progeny tests of tannin and caffeine contents of 'MAKURA No. 1' proceeded in 1994 using progenies of 'Kanayamidori (var. sinensis) × MAKURA No. 1', 'Himemidori (var. sinensis) $\times$ MAKURA No. 1', 'Asatsuyu (var. sinensis) $\times$ MAKURA No. 1' and 'NN27 (var. sinensis) $\times$ MAKURA No. 1'. The analysis of tannin and caffeine was done by near-infrared spectroscopy (NIR).

Progeny tests of aroma were performed by sensory tests using progenies of 'Kanayamidori $\times$ MAKURA No. 1', 'Himemidori $\times$ MAKURA No. 1' and 'Asatsuyu $\times$ MAKURA No. 1' in 1995.

\section{Results}

1. Tannin and caffeine contents in tea genetic resources of Makurazaki (NIVTS)

Tannin contents ranged from 11.69 to $26.82 \%$ in var. assamica, from 11.32 to $22.21 \%$ in var. sinensis (China group) and from 9.37 to $20.00 \%$ in var. sinensis (Japan group). Tannin contents were less than $25 \%$ in $99.0 \%$ of all individuals (Fig. 1).

Caffeine contents ranged from 2.39 to $5.46 \%$ in var. assamica, from 1.64 to $4.60 \%$ in var. sinensis (China group) and from 0.82 to $3.87 \%$ in var. sinensis (Japan group). Caffeine contents were less than $5 \%$ in $99.4 \%$ of all individuals (Fig. 2).

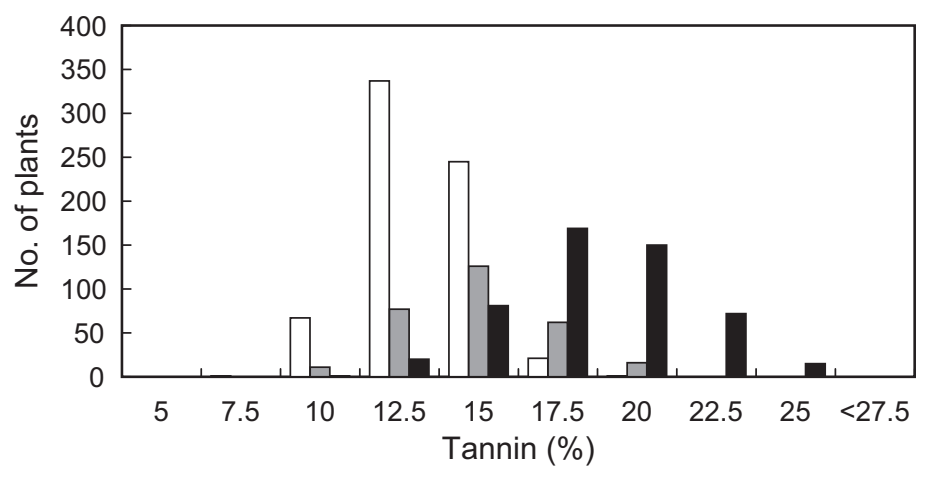

Fig. 1. Frequency distribution of tannin contents in genetic resources of Makurazaki (NIVTS)

: var. sinensis [Japan group] $(\mathrm{n}=672$, av. $=14.58 \pm 0.06)$

var. sinensis [China group] $(\mathrm{n}=292$, av. $=16.22 \pm 0.13)$

var. assamica $(\mathrm{n}=508$, av. $=19.79 \pm 0.12)$

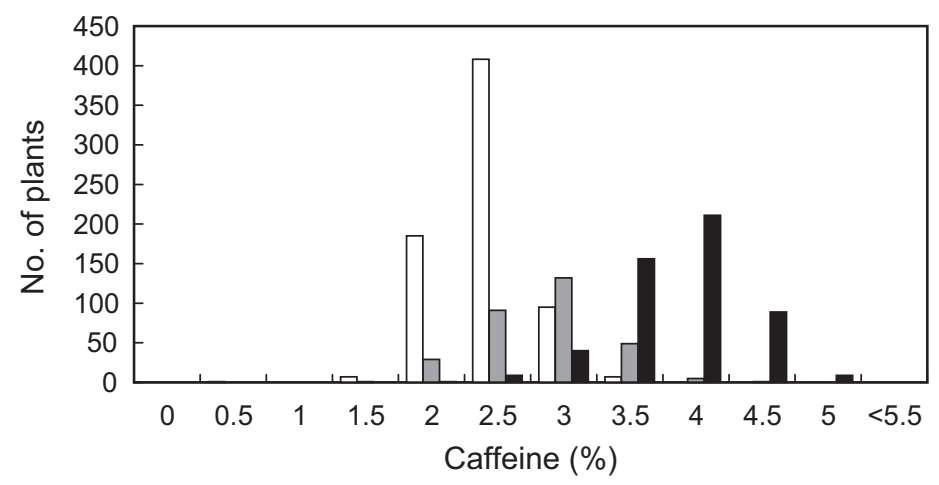

Fig. 2. Frequency distribution of caffeine contents in genetic resources at Makurazaki (NIVTS)

: var. sinensis [Japan group] $(\mathrm{n}=703$, av. $=2.68 \pm 0.01)$

var. sinensis [China group] $(\mathrm{n}=308$, av. $=3.09 \pm 0.03)$

var. assamica $(\mathrm{n}=515$, av. $=4.09 \pm 0.02)$ 
There was a positive correlation $(\mathrm{r}=0.741)$ between tannin and caffeine contents (Fig. 3). We then screened individuals with tannin and caffeine contents of more than 25 and $5.0 \%$, respectively. We found one clone with high tannin and caffeine contents and named it 'MAKURA No. 1'. Tannin and caffeine contents of 'MAKURA No. 1' were investigated in 1988, 1992, 1993, and 1994. Tannin contents ranged from 23.36 to $30.70 \%$ (average content of $26.42 \%$ ) and caffeine contents ranged from 4.98 to $5.91 \%$ (average content of 5.50\%) (Fig. 3, Table 1).

\section{Composition of catechins in 'MAKURA No. 1'}

The amounts of major catechins ((-)-epicatechin

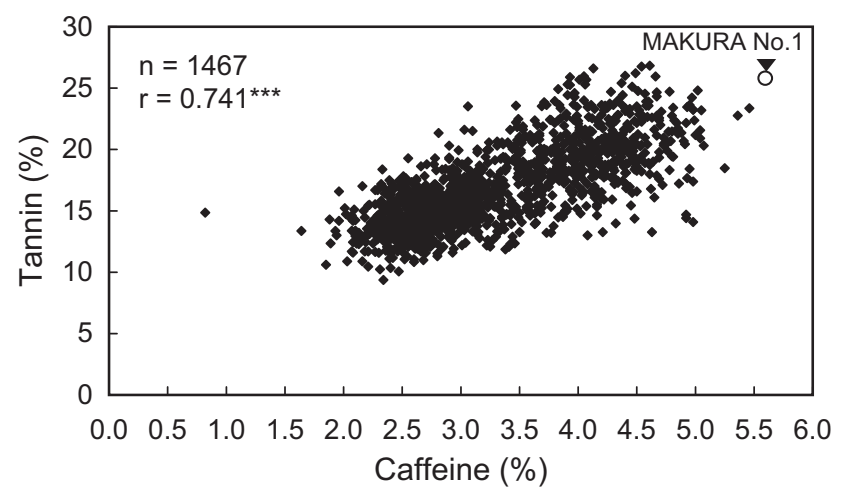

Fig. 3. Correlation of tannin with caffeine contents of new shoots in genetic resources of Makurazaki (NIVTS) $* * *$ : Significant at $0.1 \%$ level.
[EC], (-)-epicatechin gallate [ECG], (-)-epigallocatechin [EGC], (-)-epigallocatechin gallate [EGCG], and $(+)$-catechin $[+\mathrm{C}])$ showed strong correlations with tannin ${ }^{6}$. The content of catechins in the first crop of 'MAKURA No. 1' was compared with those in 'Yabukita' (var. sinensis) and 'Ryofu' (var. sinensis) in 1999. The amount of catechins in 'MAKURA No. 1' was $22.78 \%$, about two-times greater than the amount in 'Yabukita' and 'Ryofu'. EGCG is the largest ingredient in tea leaves and is one of the highest functional constituents. The ratios of EGCG in 'Yabukita' and 'Ryofu' were less than $55 \%$ of the amounts of the main catechins. However, the content of EGCG in 'MAKURA No. 1' was $60 \%$ (Table 2 ).

Table 1. Tannin and caffeine contents of MAKURA No. 1

\begin{tabular}{lccc}
\hline \hline Cultivar & $\begin{array}{c}\text { No. of plants } \\
\text { analyzed }\end{array}$ & $\begin{array}{l}\text { Tannin } \\
\text { content* }\end{array}$ & $\begin{array}{l}\text { Caffeine } \\
\text { content* }\end{array}$ \\
\hline MAKURA No. 1 & 4 & $26.4 \pm 3.1$ & $5.50 \pm 0.48$ \\
Yabukita & 5 & $14.4 \pm 2.5$ & $2.76 \pm 0.31$ \\
Kanayamidori & 3 & $13.8 \pm 2.1$ & $2.85 \pm 0.32$
\end{tabular}

Analysis had been carried out from 1988 to 1994.

*: Percentage content ; \% average dry weight of tea \pm standard deviation.

Table 2. Catechin components of MAKURA No. 1

\begin{tabular}{lccccccc}
\hline \hline Cultivar & EGC & + C & EC & EGCG & ECG & $\begin{array}{r}\text { The amount } \\
\text { catechins }\end{array}$ & $\begin{array}{c}\text { Ratio of } \\
\text { EGCG }(\%)\end{array}$ \\
\hline MAKURA No. 1 & 5.74 & 0.51 & 1.02 & 13.68 & 1.83 & 22.78 & 60.05 \\
Yabukita & 3.00 & 0.32 & 0.77 & 5.62 & 0.69 & 10.40 & 54.04 \\
Ryofu & 2.66 & 0.38 & 0.91 & 5.00 & 0.74 & 9.69 & 51.60
\end{tabular}

Analysis was carried out by using first shoots in 1999.

EGC: (-)-epigallocatechin, +C: (+)-catechin, EC: (-)-epicatechin, EGCG: (-)-epigallocatechin gallate, ECG: epicatechin gallate.

Table 3. Resistance to freezing injury in MAKURA No. 1

\begin{tabular}{lc}
\hline \hline Cultivar & Grade of resistance* \\
\hline MAKURA No. 1 & 4.0 \\
Asatsuyu & 5.5 \\
Himemidori & 6.5 \\
Kanayamidori & 8.0 \\
NN27 & 8.0 \\
\hline
\end{tabular}

*: 2 (very weak) to 8 (very strong).

Examination was carried out on January 30 in 1994. 

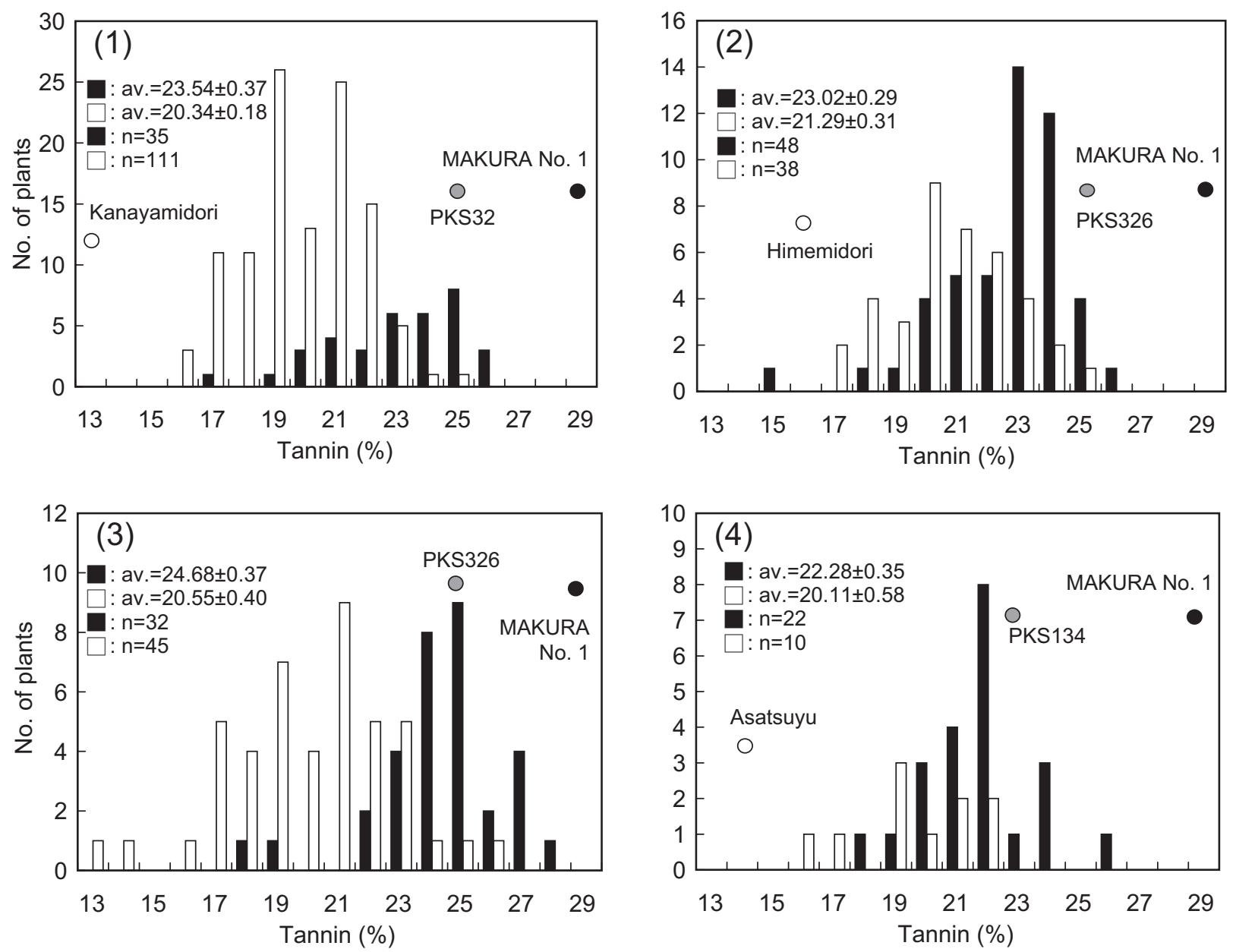

Fig. 4. Segregation for tannin contents in progenies of MAKURA No. 1

(1) : $\square$ Kanayamidori $\times$ MAKURA No. 1, $\square$ Kanayamidori $\times$ PKS326.

(2) : $\square$ Himemidori $\times$ MAKURA No. 1, $\square$ Himemidori $\times$ PKS326.

(3) : $\square$ NN27 $\times$ MAKURA No. 1, $\square$ NN27 $\times$ PKS326.

(4) : Asatsuyu $\times$ MAKURA No. 1, $\square$ Asatsuyu $\times$ PKS134.

3. Tannin and caffeine contents in progenies of 'MAKURA No. 1'

Tea (Camellia sinensis) is generally divided into two varieties, $C$. sinensis var. assamica and $C$. sinensis var. sinensis'. 'MAKURA No. 1' which is var. assamica, is sensitive to low temperature (Table 3). The areas in which this cultivar can be grown in Japan are therefore limited.

Tannin and caffeine contents in progenies of 'MAKURA No. 1' were investigated in 1994. 'Kanayamidori', 'Himemidori', 'NN27', and 'Asatsuyu' were used for seed parents. 'PKS326' (C. sinensis var. assamica) was used as a pollen parent to 'Kanayamidori', 'Himemidori' and 'NN27', and 'PKS134' (C. sinensis var. assamica) was used as a pollen parent to 'Asatsuyu'. 'PKS326' and 'PKS134' are high in tannin content as is 'MAKURA No. 1' and also have vigorous growth. Tan- nin contents of cross combinations were 23.54, 23.02, 24.68 and $22.28 \%$, respectively (Fig. 4), and caffeine contents were $4.26,4.18,4.24$ and $4.08 \%$, respectively (Fig. 5). The results show that contents of both components of progenies in 'MAKURA No. 1' were higher than those in 'PKS326' and 'PKS134' used as pollen parents. Contents of tannin and caffeine have a positive correlation, and there were two individuals in which tannin and caffeine contents were more than 25.0 and $5.0 \%$, respectively, in the progenies of 'MAKURA No. 1'.

\section{Characteristics of aroma and its inheritance in 'MAKURA No. 1'}

Some individuals in var. assamica have a characteristic flavor different from Japanese cultivars, and Y. Yanase (1987) reported that this characteristic flavor is inherited by progenies ${ }^{13}$. 'MAKURA No. 1' has a flow- 

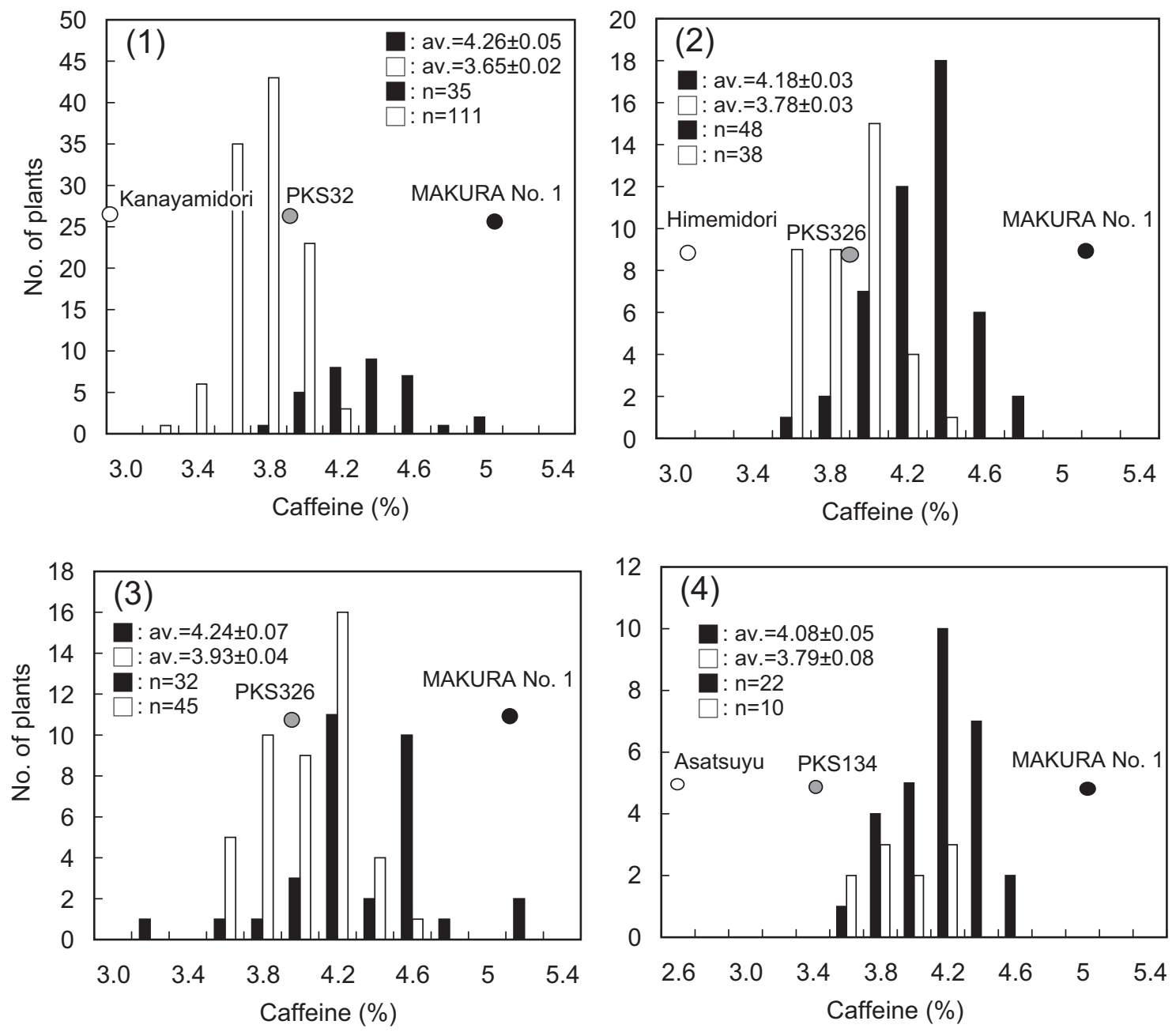

Fig. 5. Segregation for caffeine contents in progenies of MAKURA No. 1

(1) : $\square$ Kanayamidori $\times$ MAKURA No. 1, $\square$ Kanayamidori $\times$ PKS326.

(2) : $\square$ Himemidori $\times$ MAKURA No. 1, $\square$ Himemidori $\times$ PKS326.

(3) : $\square$ NN27 $\times$ MAKURA No. 1, $\square$ NN27 $\times$ PKS326.

(4) : $\square$ Asatsuyu $\times$ MAKURA No. 1, $\square$ Asatsuyu $\times$ PKS134.

Table 4. Chi-square test on segregation ratio of flowery flavor in the progenies of MAKURA No. 1

\begin{tabular}{|c|c|c|c|c|c|c|c|}
\hline \multirow[t]{2}{*}{ Cross combination } & \multirow{2}{*}{$\begin{array}{l}\text { No. of } \\
\text { plants }\end{array}$} & \multicolumn{2}{|c|}{ Positive $(+)$} & \multicolumn{2}{|c|}{ Negative (-) } & \multirow{2}{*}{$\begin{array}{c}\text { Value of } \\
\text { Chi-square } \\
\quad(1: 3)\end{array}$} & \multirow[t]{2}{*}{ Probability } \\
\hline & & $\begin{array}{c}\text { Value of } \\
\text { observation }\end{array}$ & $\begin{array}{l}\text { Value of } \\
\text { expectation }\end{array}$ & $\begin{array}{c}\text { Value of } \\
\text { observation }\end{array}$ & $\begin{array}{l}\text { Value of } \\
\text { expectation }\end{array}$ & & \\
\hline Asatsuyu × MAKURA No. 1 & 28 & 10 & 7.00 & 18 & 21.00 & 1.714 & $0.10-0.20$ \\
\hline Kanayamidori × MAKURA No. 1 & 35 & 6 & 8.75 & 29 & 26.25 & 1.152 & $0.20-0.30$ \\
\hline Himemidori × MAKURA No. 1 & 49 & 11 & 12.25 & 38 & 36.75 & 0.170 & $0.50-0.70$ \\
\hline
\end{tabular}

The sensory test was carried out by using brewed tea (4th shoots) in 1995.

ery flavor, and this flavor was able to be easily distinguished by a sensory test. The incidence of this flavor was $35.7 \%$ (Asatsuyu $\times$ MAKURA No. 1), $17.1 \%$ (Kanayamidori $\times$ MAKURA No. 1) and $22.4 \%$ (Himemidori $\times$ MAKURA No. 1). The result of the chi-square test could not reject the null hypothesis that the segregation ratio of positive and negative was 3 to 1 . Therefore, we predicted that this aroma will be inherited from 'MAKURA No. 1' by a major gene (Table 4). 


\section{Discussion}

Tannin and caffeine contents in tea leaves differ depending on the climate, plucking period, fertilizer and many other factors. However, both components in 'MAKURA No. 1' had been the highest ones in Makurazaki (NIVTS) at any time. Moreover, both tannin and caffeine contents of some progenies in 'MAKURA No. 1' were more than 25 and $5.0 \%$, respectively, although there were no individuals in the genetic resources at Makurazaki except for 'MAKURA No. 1' in which both tannin and caffeine contents were more than 25 and $5.0 \%$, respectively. This clearly shows that 'MAKURA No. 1' is a cultivar with high tannin and caffeine contents and that it could be an excellent parental line for breeding cultivars with high contents of tannin and caffeine.

EGCG is the major catechin of tea and is well known as a functional component. The ratio of EGCG in 'MAKURA No. 1' is high (Table 2), indicating that 'MAKURA No. 1' is a suitable cultivar for breeding the extraction material of catechins.

Methyl anthranilate (MeA) is a floral scent component in several plants ${ }^{3,5}$, the characteristic flowery flavor of 'MAKURA No. 1' is caused by $\mathrm{MeA}^{4}$. We can easily select flowery flavor (due to MeA) individuals from the progenies of 'MAKURA No. 1'.

Tea genetic resources have been introduced from many countries since 1875 . 'MAKURA No. 1 ' is one of the genetic resources introduced from India by Dr. Niro Tomo in 1964, and it has been preserved in Makurazaki (NIVTS). However, foreign genetic resources have rarely been used for breeding Japanese green tea and high functional tea cultivars.

Functional compounds of tea have come into the spotlight recently ${ }^{1}$. It is therefore necessary to raise tea cultivars with various flavors and tastes and with functional components to satisfy recent consumer needs. We can say that 'MAKURA No. 1' is the first cultivar targeting specific chemical constituents in Japan.

\section{Acknowledgments}

We are grateful to Mr. Kosei Wada (National Research Institute of Vegetables, Ornamental Plants and Tea) for sensory test of brewed tea and Mr. Yuichi Yamaguchi (National Institute of Vegetable and Tea Science) for the analysis of catechins. This work was supported by the Bio-Renaissance Program (1991-2000) from the Ministry of Agriculture, Forestry and Fisheries of Japan.

\section{References}

1. Hakamata, K. (1993) The development of new products and the enlargement of utilization in tea. Nourinsuisan gijutsu kenkyu journal (Res. J. of Food \& Agric.), 16 (6), 30-34 [In Japanese].

2. Ikegaya, K., Takayanagi, H. \& Anan, T. (1990) Quantitative analysis of tea constituents. Chagyo kenkyu hokoku (Tea Res. J.), 71, 43-74 [In Japanese].

3. Imai, T. et al. (2001) Attractiveness of methyl anthranilate and its related compounds to the flower thrips, Thrips hawaiiensis (Morgan), T. coloratus Schmutz, T. flavus Schrank and Megalurothrips distalis (Karny) (Thysanoptera: Thripidae). Appl. Entomol. Zool., 36 (4), 475-478.

4. Tanaka, J. \& Sawai, Y. (2005) Mat locus control the existence of an aromatic substance methyl anthranilate in tea leaves, derived from clonal strain 'Shizu-Inzatsu 131'. In Yasaichagyo kenkyuseika johou (Res. Results of Veg. \& Tea Sci.), National Agricultural and Bio-oriented Research Organization, Tsukuba, Japan, 75-76 [In Japanese].

5. Knudsen, J. T., Tollsten, L. \& Bergström, L. G. (1993) Floral scents - a checklist of volatile compounds isolated by head-space techniques. Phytochemistry, 33, 253-280.

6. Nakagawa, M. (1970) Relation of catechins with the qualities of green and black tea. Chagyo shikenjo kenkyu hokoku (Bull. of Tea Res. Stn.), 6, 65-166 [In Japanese with English summary].

7. Nakagawa, M. (1973) Relation of constituents with taste of green tea. Chagyo kenkyu hokoku (Tea Res. J.), 40, 19 [In Japanese].

8. Saijo, R. (1993) Present status and future aspects of the studies on the third function of tea drinking. Nourinsuisan gijutsu kenkyu journal (Res. J. of Food \& Agric.), 16(6), 35-39 [In Japanese].

9. Sealy, J. R. (1958) A revision of the genus Camellia. Royal Horticulture Society, London, 34-35.

10. Takeda, Y. (1993) Targets and future plans of tea breeding. Nourinsuisan gijutsu kenkyu journal (Res. J. of Food \& Agric.), 16 (6), 7-11.

11. Yamaguchi, Y., Yamamoto, M. M. \& Tsuji, K. (1997) HPLC analysis of catechins and caffeine in tea extract with catechol as an internal standard. Chagyo kenkyu hokoku (Tea Res. J.), 84, 32-34 [In Japanese].

12. Yamamoto, M. M. (1996) Physiological modulative functions of tea. Nippon shokuhin kagaku kogaku kaishi (J. Jpn. Soc. Food Sci. \& Technol.), 43, 653-662 [In Japanese].

13. Yanase, Y. (1987) Search a new type of tea with a characteristic flavor from $C$. sinensis var. assamica and its hybrids. Kenkyuseika (Res. Results), 187, 113-118 [In Japanese]. 